\title{
Effects of Guilt, Disbelief, and Assessed Lie-Truth Telling Abilities on Physiological Responses in the Guilty Action Test
}

\author{
Eitan Elaad*, Eliane Sommerfeld \\ Department of Behavioral Sciences, Ariel University, Ariel, Israel \\ Email: *elade@ariel.ac.il
}

Received 21 May 2016; accepted 11 July 2016; published 14 July 2016

Copyright (C) 2016 by authors and Scientific Research Publishing Inc.

This work is licensed under the Creative Commons Attribution International License (CC BY). http://creativecommons.org/licenses/by/4.0/

\section{Abstract}

This experiment used a mock crime procedure in which 100 participants were randomly assigned to four experimental conditions in a $2 \times 2$ factorial design. Two guilt conditions (guilty and informed innocents) were crossed with two human interrogation feedback conditions (believed and not believed). The Guilty Action polygraph test was administered several days after the mock crime and the human interrogation. Along with the common dependent polygraph measures (electro dermal, respiration, and cardiovascular measures), self-assessments of the ability to tell lies and to tell the truths convincingly, were gathered. Results showed enhanced responses to the critical items for all three physiological measures. Respiration responses significantly differentiated between guilty and informed innocent participants. No significant guilt effect was obtained for electro dermal and cardiovascular responses. The feedback manipulation failed to affect all three physiological responses. Informed innocent participants who rated low their ability to tell the truth convincingly elicited larger electro dermal responses to critical items than high raters. Guilty participants who rated high their lie telling ability showed larger electro dermal responses to critical items than low raters. Further research on the association between self-assessment of lie and truth telling abilities and physiological responsivity in the Guilty Action Test is recommended.

\section{Keywords}

Concealed Information Test, Guilty Action Test, Lie-Detection, Disbelief, Polygraph

\footnotetext{
${ }^{*}$ Corresponding author.
} 


\section{Introduction}

The Concealed Information Test (CIT) is a psycho physiological memory detection method used in criminal interrogations to uncover information that the suspect tries to hide (Lykken, 1974, 1998). In the CIT, examinees are presented with series of items. In each series, one item is relevant to the interrogated crime, whereas the other items serve as controls. Based on the assumption that only a guilty person knows the details of the crime, enhanced responsivity to critical items indicates recognition and may imply involvement. The innocent suspect, for whom all items are neutral, is expected to respond much less to the critical items.

Research on the CIT in laboratory settings is intensive and has revealed highly accurate confirmation for both guilty and innocent examinees (see reviews by Ben-Shakhar \& Elaad, 2003; Mejer, Klein-Selle, Elber, \& BenShakhar, 2014). There is also agreement among scientists that the CIT is grounded in solid theoretical foundations (e.g., Verschuere \& Ben-Shakhar, 2011; Ben-Shakhar, 2012). Specifically, the Orienting Response (OR) theory (Sokolov, 1963; Lynn, 1966) was proposed to account for the CIT effect. According to OR theory, for the guilty examinee the critical items have an added signal value and therefore are more meaningful than the controls and the significance of the critical items elicits enhanced ORs. For innocent examinees all items are equivalent in significance and, therefore, the ORs are not systematically different in magnitude (Lykken, 1974). More recently, an alternative theory, the Response Inhibition (RI) theory, has been proposed to account for observations that did not reconcile with the OR theory (Verschuere et al., 2007). The RI theory suggests that in the CIT context inhibition represents either suppression of the truthful answer or inhibition of the arousal that follows an OR. Specifically, guilty suspects who recognize the link between the critical items and the crime under investigation try to inhibit the physiological arousal that accompanies the OR. This paradoxically results in differential physiological responding. The effects were previously demonstrated while using the P300 Event Related Potential (ERP) for individuals trying to simulate amnesia (Ellwanger, Rosenfeld, Sweet, \& Bhatt, 1996). A recent account (Klein-Selle, Verschuere, Kindt, Meijer, \& Ben-Shakhar, 2016), suggested that in the context of the CIT different mechanisms drive the responding of different psycho physiological measures with skin conductance reflecting OR and heart rate and respiration primarily reflecting RI.

However, most of the evidence about CIT validity is derived from studies conducted in artificial laboratory settings. Here, participants volunteer to take part in the study knowing that whatever the outcome, it will have no consequences to their well-being. Therefore, their emotional stress and motivation to succeed are lower than in actual testing scenarios. Furthermore, in many mock-crime studies the experimenter guarantees that all the participants who simulate guilt are fully aware of the critical alternatives. Thus poor memory of critical information, which may present difficulties to the CIT detection, is avoided when the CIT is executed without delay.

Attempts to control for some of these limitations were reported. Several studies examined the validity of the CIT in experimental settings while applying more realistic CIT situations. Specifically, there was no explicit specification of the critical items and participants were not allowed to rehearse these items before the test. Furthermore, the execution of the CIT was delayed (e.g., Carmel et al., 2003; Elaad, 1997; Gamer et al., 2010; Nahari \& Ben-Shakhar, 2011). Results revealed that when the CIT is performed 1 or 2 weeks after the mock crime, some critical items of information are forgotten and consequently fail to elicit differential physiological responses. However, memory impairment occurs mostly with peripheral or less pertinent details. We adopted this line of research in the current study. The CIT was delayed for 1 - 14 days and participants were not reminded of the critical items before the polygraph test.

\section{Detection of Information among Innocent Examinees}

Still most of the laboratory studies assume that only guilty suspects hold crime-related information while innocent suspects are absolutely unaware of it. However, this is not the case in actual settings. Information about the crime might leak and reach innocent suspects from different sources. For example, critical information might leak from the mass media while describing the crime, through the internet, through contact with other knowledgeable people and even during interrogation itself. The effect of information leakage on the test accuracy was examined in several studies (Bradley, MacLaren, \& Carle 1996; Bradley \& Rettinger, 1992; Bradley \& Warfield, 1984; Zvi, Nachson, \& Elaad, 2012, 2015). Generally, results showed that informed innocent examinees exhibited larger responses to the critical items than unknowledgeable innocents. Still, informed innocents could be differentiated from guilty participants. Other studies reported that informed innocents were differentiated from guilty examinees only when the CIT was delayed but not when the test was performed immediately after the 
mock crime (Gamer, 2010; Nahari \& Ben-Shakhar, 2011). These results may suggest forgetting: informed innocents forgot more critical items than guilty examinees in the delayed session, while memory of guilty and innocents stay intact in immediate testing. Additional research on the informed innocent issue is necessary to clarify this matter and the present study will contribute in this respect.

To deal with the damaging leakage effects, Bradley and Warfield (1984) proposed to modify the CIT and change the wording of the question from passive knowledge (e.g., "Was the color of the stolen envelope...?”) to active involvement (e.g., "Was the color of the envelope you stole...?”). They labeled the new version: Guilty Action Test (GAT). Bradley and Warfield showed that the detection rates of guilty participants by the GAT were higher than those of informed innocents. However, this result is controversial (e.g., Gamer, 2010). The present study will use both informed innocents and the GAT version of the CIT.

\section{Presumption of Guilt and Disbelief of the Investigator}

Another prominent factor that influences the CIT outcomes and was ignored by all previous laboratory studies is the disbelief that the investigator expresses during the interrogation phase, long before the polygraph test. Previous studies incorporated negative feedback during the CIT (e.g. Rosenfeld, Hu, \& Pedersen, 2012; Sai et al., 2016), yet, the drive of examinees who prepare for a polygraph test under the impression that the investigator does not believe them is different than that of examinees who receive feedback of disbelief during the test.

Kassin (2005) noted that he interviewed many police investigators who believe that they never interrogate innocent suspects. This presumption of guilt appears to increase with training and experience (Meissner \& Kassin, 2002). Hence the probability of experienced police investigators to judge suspects as deceitful increases. One focus of the current study is on disbelief; specifically, on studying the differential effects of interrogators' explicit belief or disbelief on the subsequent physiological responses in the CIT. The inclusion of a human interrogation routine several days before performing the CIT better approximates a realistic CIT situation.

\section{Self-Assessed Abilities to Tell Lies and Truths}

Investigators disbelief may be related to the overestimated confidence of police investigators in their lie-detection ability (e.g., Elaad, 2003, 2009). However, the bias was also observed among adolescents (Elaad et al., 2012) and laypersons (Elaad, 2009), but not among students (e.g., Elaad, 2011). The bias was explained by the prevailing norms that dictate people not to allow themselves to be easily deceived (Elaad, 2009). In addition, people would like to be able to detect lies. Accordingly, various groups of people self-assess themselves as better lie-detectors than other people.

People consistently rate as high their own ability to be convincing when telling the truth (e.g., Elaad, 2009, 2011). This bias maintains the human desire to sustain a positive self-image (Kaplar \& Gordon, 2004). The ability to convince when telling the truth is a desirable quality.

The lie-telling bias or the extremely low assessment of the ability to tell-lies (Ekman \& O'Sullivan, 1991; Elaad, 2003, 2011; Vrij, 2008) preserves the desire to sustain a positive self-image. Specifically, if I am not an able lie-teller I am an honest person. However, Elaad (2009) reported of a sample of police investigators who rated their lie-telling ability higher than other individuals.

The polygraph has a reputation as a lie-detector. In this context guilty participants who assess high their ability to tell lies convincingly have the opportunity to test their skills and are motivated to avoid detection. It was previously demonstrated that such a motivation increases attention to the recognized items and enhances relative physiological responding to these items (see Elaad \& Ben-Shakhar, 2003 for a review). Guilty participants who evaluate low their lie-telling ability may resign and be less motivated to avoid detection. Their attention is less focused on the critical items and so is their physiological responding. The assessed lie-telling ability is not expected to affect the responses of informed innocent participants when the GAT procedure is applied.

The truth-telling ability will negatively affect the responses of informed innocents. Specifically, Innocent participants, who assess low their ability to tell the truth convincingly and deny involvement with the critical items on the GAT, may be concerned that they are not convincing. This will increase attention to the critical items and enhance their physiological responses to these items. Innocent participants who have confidence in their ability to convince others when telling the truth may rely on their skills and resign. Consequently, their relative physiological responses to the critical items will decrease. The assessed truth-telling ability is not expected to affect responses of guilty participants in the GAT. 


\section{Hypotheses of the Present Study}

The following is a summary of our hypotheses: As for situational factors, guilty participants will remember more critical items than informed innocents. This will lead to enhanced responses to critical items produced by guilty examinees in the polygraph test. Human interrogation will have an immediately strong influence on participants, but the time intervention until the execution of polygraph test may attenuate these effects on the physiological responses. Still the interrogators' disbelief towards informed innocents will be associated with enhanced physiological responsivity. As to individual factors, the perceived ability of being convincing when telling the truth will be assessed as extremely high, whereas the ability of being convincing when lying will be assessed as rather low. These two perceived abilities will differently influence physiological responding. High self-assessed lie telling ability will predict larger responding of guilty participants to critical items. Low self-assessed truth telling ability will predict larger responding of informed innocent participants to critical items.

\section{Method}

\subsection{Participants}

One hundred undergraduate psychology students participated in the present study for course credit. Participants (84 females) were recruited through ads placed on bulletin boards throughout the campus. Thirty two participants were religious, twenty-six were traditional and forty two were secular. All participants had no past experience with criminal interrogation. Their age ranged between 19 - 30 years with a mean age of $23.2(S D=1.81)$ years. Some participants were entitled to additional course credit for truthful classification on the test.

\subsection{Design}

A $2 \times 2$ between-subjects design was used with two factors: guilt (guilty vs. informed innocent participants) and investigator feedback (belief vs. disbelief). By combining both factors four experimental conditions were formed: (1) guilty participants who were involved in a mock theft and were believed by the interrogator while denying committing the crime; (2) guilty participants who were involved in a mock theft and received feedback of disbelief; (3) informed innocent participants who were not involved in the crime, and were believed when denying involvement; and (4) informed innocent participants who were not involved in the crime, but were disbelieved. The dependent variables were three commonly used physiological indices (skin conductance, respiration changes, and finger pulse activity). Participants were randomly assigned to the four conditions, 25 participants in each condition.

\subsection{Apparatus}

Since the apparatus of the present study was identical to that described in our previous accounts (e.g., Elaad, 2013), we repeated that description as follows: "Three physiological measures were used to examine GAT accuracy: (a) amplitude of the skin conductance response (SCR); (b) respiration line length (RLL); (c) finger pulse waveform length (FPWL). All these indices were used before in similar studies and proved to be valid indicators of the changes that the CIT (and GAT) measures (e.g. Elaad, 2010, 2013). Skin conductance response was measured by a constant voltage system (.5 V Atlas Researches Ltd., Israel). Two Ag/AgCl Grass electrodes (.8 $\mathrm{cm}$ diameter) were attached to the index and fourth fingers of the participants' left hand using Johnson and Johnson K-Y jelly. Respiration line length responses were recorded by an Atlas Researchers piezoelectric belt positioned around the thoracic area. Two additional covert respiration measures were recorded by respiratory piezoelectric effort transducers (Atlas Researchers) concealed in the back support of the polygraph examination chair and in the seat (Elaad \& Ben-Shakhar, 2008). Elaad and Ben-Shakhar (2008) reported that the covert back respiration measure elicited similar responses to those elicited by the standard belt measure. Unfortunately, in many cases the recordings of the standard respiration measure were not properly registered due to technical problems. It was therefore decided to replace them with the covert back recordings. From here on, the term RLL refers to covert respiration back recordings. Finger pulse waveform length responses (FPWL) (Elaad \& BenShakhar, 2006) were recorded using an Atlas Researches (Israel) piezoelectric plethysmograph positioned around the right thumb. The plethysmograph measures pressure changes accompanying the blood volume pulse. An increase in these values represents vasodilation, whereas a decrease reflects vasoconstriction. FPWL also 
entails pulse rate changes.

The experiment was conducted in an air-conditioned laboratory and monitored from a control room separated from the laboratory by a one-way mirror. A serial communication link from DAS (Data Acquisition System) was split in parallel into the serial ports of two PC computers. One computer controlled the stimulus presentation and computed skin conductance, respiration and cardiovascular changes. The stimuli were displayed on a 15 "color monitor positioned in front of the participant. The second computer displayed physiological responses in real time in the form of graphs on a 15" color monitor positioned in front of the experimenter located in the control room. The graphs were recorded for subsequent visual analysis and artifact control”.

\subsection{Procedure}

Approval for the present experiment was obtained from the ethics committee of Ariel University. The experiment was conducted in two sessions separated by $1-14$ days (mean $=5.17, \mathrm{SD}=3.25$ days) to better resemble the variability in actual testing. Two experimenters who performed two different roles (i.e., role-switching) handled the first session. The first experimenter welcomed the participants individually and informed them about the upcoming lie detection study. She further explained that two separate sessions were planned. In the first, participants would be interrogated by a human interrogator about a mock crime and in the second session they would be tested with the polygraph. Participants were then asked for their name, gender, age, level of religiosity, and past experience with interrogations. Participants were further asked to complete a consent form through the signing of which they indicated their agreement to participate in the two sessions of the experiment. In the consent form they were assured of confidentiality and anonymity. They were also told that they could end their participation in the experiment at any time.

Participants were asked to self-assess their own lie-detection, lie-telling, truth-telling and truth-believing abilities relative to other people. Assessments were made on a scale with two end points: 0 (much worse than others) and 100 (much better than others) and a middle point 50 (as good as others) (see Elaad, 2009 for details).

\subsection{Guilt and Innocence Manipulations}

Participants who were assigned to the simulated guilt condition received an explanation of the human and polygraph interrogations they will undergo. They were told that the study was designed to find out whether, and to what extent, they can avoid detection of their involvement with the crime by a human interrogator and later by the polygraph. To this end, they were warned not to disclose any detail that may link them with the crime at any part of the experiment.

The first experimenter told them to take one of six closed envelopes placed on the table. The envelopes contained instruction sheets which participants had to read and follow after leaving the room. The experimenter warned the participants that any failure to follow the instructions would result in terminating the experiment and losing the promised course credit for the subsequent second session of the experiment. The experimenter handed the participants a key to another room on the same floor and told them to return after the completion of the task.

The written instructions ordered participants to commit a mock-theft in the other room. They were instructed to unlock the door, get in, open a drawer, take the envelope inside, and open it.

The crime details were identical to those described in a previous study conducted in our laboratory (Zvi et al., 2012): "One of four alternative crime details was presented to the participant: (a) a yellow envelope addressed to the research authority containing NIS57, a necklace, a calculator, and a photograph of a bear; (b) a green envelope addressed to the computer department containing NIS24, aring, apen, and a photograph of a rhinoceros; (c) ared envelope addressed to the security officer containing NIS49, a pair of earrings, spectacles, and a photograph of a zebra; and (d) a blue envelope addressed to the academic secretary containing NIS63, a bracelet, a key, and a photograph of a lion (The critical items are marked in italics)”.

The assignment of a given profile to the participant was random. This is demonstrated by the insignificant results of a chi-square test for independence on the profiles' frequencies in the four experimental conditions, $\chi^{2}{ }_{(9)}=$ 3.36, ns.

"A fifth profile of neutral control items (a gray envelope addressed to the student dean, containing 31 NIS, a watch, a camera, and a photograph of a vulture) was added to be used in the polygraph test. Finally, a sixth buffer profile of neutral items (a black envelope addressed to the finance section, containing 16 NIS, a pendant, cell 
phone, and a photograph of an elephant) was formed to follow the presentation of each question in the polygraph test in order to absorb the initial orienting response".

The participants were instructed to open the envelope, check its contents and compare it to a check list on the instruction sheet. They then were instructed to put the contents back in the envelope and hide it in a fire box. They then returned to the experimenter.

Informed innocent participants were told by the experimenter that the study was designed to find out whether they could prove their innocence when interrogated by a human investigator and by the polygraph. The participants were asked to take an envelope containing an instruction sheet, and leave the room. Once outside, they read that there is a rumor that a theft was committed nearby. A detailed description of the alleged stolen envelope and its assumed contents was provided. The participants were instructed to wait for three minutes and then return to the experimenter.

Upon returning, the experimenter told all participants that they were suspected as thieves because they were seen near the office from which the envelope was stolen and that the following human interrogation by an experienced interrogator would determine if they committed the mock theft. To check if the participants understood the instructions, the experimenter asked them if they stole the envelope and the money. Most participants answered "no". The few who replied "yes" were warned again. Then, the experimenter directed the participants to a third room further away, were the interrogator (a second experimenter), who conducted the human interrogation, was seated.

\subsection{The Human Interrogation and Feedback of Belief/Disbelief}

Participants arrived at the indicated office for the human interrogation. The neatly dressed interrogator, who was unaware of the guilt condition to which the participant was assigned, asked for the name of the participant followed by an open question: "What brought you here?" The common answer was: "I am suspected of stealing an envelope from a nearby office.” The interrogator further asked: "Did you steal the envelope with its contents?” The interrogator wrote down the answer. The interrogator then revealed his/her experience in interrogating people, and noted: “My job is to find out if you took the envelope with its contents that you claim you didn't steal”.

Seven additional questions followed:

Do you definitely know where the stolen envelope is hidden? (no)

Do you definitely know how much money was in the stolen envelope? (no)

Do you definitely know the color of the stolen envelope? (no)

Do you definitely know to whom the stolen envelope was addressed? (no)

Do you definitely know what jewelry was in the stolen envelope? (no)

Do you definitely know which picture was in the stolen envelope? (no)

Do you definitely know what was the other object placed in the stolen envelope? (no)

After every answer the interrogator closely inspected the participant and wrote the answer down on the sheet placed in front of him/her.

It should be noted that guilty participants lied to all the above questions. Innocents were truthful when denying involvement in the theft and when denying knowledge about where the envelope was hidden. Still, they were informed of the alleged stolen articles, and although uncertain (knowledge was based on a rumor) it is still possible that some have felt that their responses were not entirely truthful.

Half of the guilty and half of the informed innocents engaged in the following interaction: "I wrote down your answers. I have experience in lie-detection and you made the impression that you are lying. I say it based on your tone of voice, your posture, and body movements." "Have you lied to me?” (no). “I don’t believe you! I am indicating my bad impression here (pointing at the sheet). Unfortunately, you are not entitled to the extra promised credit."

The other half of the guilty and informed innocents engaged in a slightly different interaction: "I wrote down your answers. I have experience in lie-detection and you made the impression that you are truthful. I say it based on your tone of voice, your postures and body movements". "Have you lied to me?” (no). "I believe you! I am indicating my good impression here (pointing at the sheet). Fortunately, you are entitled to the extra promised credit.”

After the interrogation participants returned to the first experimenter and were asked to complete the PANAS 
(Positive and Negative Affect Schedule) scale which presented 10 positive and 10 negative moods (Watson, 1988). Participants were asked to assign the extent to which they experience each particular emotion with reference to a 5-point scale. The scale points are: (1) "not at all”, (2) "a little bit”, (3) “moderately", (4) "quite a bit" and (5) "very much". Another questionnaire asked participants to evaluate several features such as their ability to control themselves under pressure, their tendency to suspect others, and being a person full of energy. Also integrated into these questions, participants were asked about their present feeling. Answers were provided on a scale ranging from bad (1) to good (9). Finally, a date was scheduled for the next stage of the experiment (the polygraph test).

\subsection{The Polygraph Test}

Participants attended the second session of the experiment between 1 - 14 days after the first session. A female experimenter, who was not involved in the previous mock crime and human interrogation, conducted the polygraph test. The experimenter welcomed the participants and recorded their name, age, and gender. She told the participants that they would undergo a polygraph test regarding a theft of a missing envelope. She then handed them a consent form to sign. The signature confirmed their willingness to be examined with the polygraph. Participants were again assured of their anonymity and privacy, and were told that they could exit the test at any time.

The experimenter, who was unaware of the participant guilt and feedback condition and of the randomly assigned critical profile, directed the participants to the examination room. The participants were invited to sit down in the examination chair, place their hands on the arms support, lean on the back support, look at the monitor in front of them, and refrain from moving during the entire test. The experimenter attached the polygraph devices while explaining the function of each device (e.g., "the device that I am attaching to your finger will record your blood flow and heart rate"). She then moved to an adjacent control room and through a speaker explained that the polygraph would reach a decision of whether or not the examinee was involved in the theft. The decision would be based on their physiological responses. She then continued as follows: "You are going to be examined with the polygraph. If the polygraph will find that you are involved in the theft of the missing envelop you will lose the extra bonus promised for a truthful outcome. It is important for you to know that the system is designed to help people prove their innocence. If innocent, you are advised to cooperate with the polygraph by adopting a relaxed and calm attitude and by following examiner instructions so as to allow the examiner to perform under the best possible conditions". Participants were further asked to sit straight and cease moving to avoid the impression that they were purposely trying to impede the test.

The experimenter reminded the participants that if successful in producing positive outcomes, they would receive an additional bonus of credits.

The following is a description of the polygraph test which is identical to that of Zvi et al. (2012): "After an initial rest period of 2 min. during which skin conductance baseline was recorded, six CIT questions were presented to the participants, each focusing on a different feature of the mock-crime (the color of the stolen envelope; the name of the addressee; the stolen sum of money; the stolen jewelry; the stolen object; and the stolen photograph). The questions were presented on a computer monitor and were read aloud to the participants from pre-recorded sound files.

Each question contained 11 items: one critical (e.g., the color of the stolen envelope) and four neutral control items (other colors of envelopes) which were presented in a random order and then repeated in a different order. A neutral buffer item (a different color), which was presented at the beginning of each question, was designed to absorb the initial orienting response. Inter-stimulus intervals ranged from 16 to 24 sec., with a mean interval of $20 \mathrm{sec}$. The questions were presented in a random sequence with a break after the first three questions, designed to give the participants the opportunity to take a deep breath and move their limbs. Subsequently, the remaining three questions were presented. Whenever necessary, the experimenter commented on the behavior of the participants in the first part of the experiment (e.g., do not yawn, do not cross your legs), and reminded them to sit straight and refrain from moving while being tested. All questions were formulated according to the GAT questioning format. For example, with relation to the stolen sum of money, the participants were asked: "Was the amount of money that you stole 75 NIS, 63 NIS etc?” The GAT format guaranteed that guilty participants lied in response to the critical items and told the truth in response to the controls. The innocent participants told the truth in response to both the critical and the neutral items".

After completion of the polygraph test all participants were asked to recall the six critical items of their profile. 
They were further asked to indicate to what extent they felt guilty or innocent (manipulation check of guilt). Answers were given on a scale ranging from 0 "completely innocent" to 100 "completely guilty". The participants were further asked to indicate how excited they were during the polygraph test. Answers were given on a scale ranging from 0 "very little" to 100 "very much". Then, the PANAS scale was administered. Next, participants were asked once again to self-assess their perceived lie/truth related abilities.

\subsection{Response Scoring and Analysis}

Participants' physiological responses were transmitted in real time to the computer. A sampling rate of 20 per second was always applied.

Electro dermal responses. SCR amplitude was computed as the maximal increase in conductance obtained from the participant, from 1 to $5 \mathrm{~s}$ after stimulus onset (Ben-Shakhar, Gronau, \& Elaad, 1999).

Finger pulse. FPWL responses were defined as the measured line length of the pattern that describes the peripheral blood vessel activity within 15 s from stimulus onset (Elaad \& Ben-Shakhar, 2006).

Respiration. Respiration responses were defined on the basis of the total respiration line length (RLL) during the $15 \mathrm{~s}$ interval following stimulus onset, where shorter lines correspond to stronger responses (see Elaad, Ginton, \& Jungman, 1992, for details)".

\section{Results}

\subsection{Manipulation Check}

Immediately after the human interrogation, participants were asked to indicate their present feelings on a scale ranging from (1) bad to (9) good. It was observed that participants who were disbelieved felt worse (mean = 6.73 , $\mathrm{SD}=1.54$ ) than participants who were believed (mean $=7.55, \mathrm{SD}=1.29$ ). The difference is significant, $\mathrm{t}_{(98)}=2.88, p=.005$. Results indicate that the human interrogation had an immediate effect on the participants.

At the end of the second session participants were asked to indicate to what extent they felt guilty/innocent during the experiment. Participants expressed their feelings on a scale with 0 indicating innocence and 100 representing guilt. Guilty participants (Mean $=57.6, \mathrm{SD}=45.3$ ) felt more guilty than innocents (Mean $=18.2$, $\mathrm{SD}=33.8)$. The difference is significant, $\mathrm{t}_{(98)}=4.9, p<.001$. Hence the guilt manipulation received support. No guilt or feedback effects on excitement were observed.

\subsection{Emotional Responses in the Two Sessions-The PANAS Questionnaire}

After the interrogation, participants completed the PANAS scale. They completed it again after the polygraph test. For each participant in each session, the mean of 10 positive and 10 negative emotions were computed. A $2 \times 2 \times 2$ ANOVA with two between subject factors-Guilt (guilty, innocents) and Feedback (belief, disbelief) and one within subject factor-Session (first, second) was performed on the negative PANAS ratings. Results revealed a significant Session $\times$ Feedback interaction effect, $\mathrm{F}_{(1,96)}=13.9, p<.001, p=.13$. The interaction indicates that investigators' disbelief in the first session resulted in relatively high ratings of negative emotions (Mean $=1.82, \mathrm{SD}=.88$ ) which decreased in the second session (Mean $=1.34, \mathrm{SD}=.57$ ). The difference is significant, $\mathrm{t}_{(49)}=4.37, p<.001$. When the interrogator believed the participants no session effects were observed. When the ANOVA was conducted on positive PANAS emotions, no significant effects were found. To conclude, disbelief enhanced negative emotions, but only in the first session, immediately after the human interrogation.

\subsection{Memory of the Critical Items}

After the polygraph test participants were asked to name the items that they remembered from the mock theft (mean $=4.35, \mathrm{SD}=1.31$ items). The obtained recall rate is lower than the corresponding rate obtained in previous studies when the polygraph test was administered immediately after the mock-crime. For example, Elaad (2015) reported a much higher recall rate (mean $=5.63, \mathrm{SD}=.68$ items). The time that elapsed from the first to the second session may explain the low number of remembered items. Finally, guilty participants remembered more critical items (Mean 4.76, $\mathrm{SD}=1.10$ ) than did informed innocents (Mean 3.94, $\mathrm{SD}=1.38$ ). The difference is significant, $\mathrm{t}_{(178)}=3.29, p=.001$. Feedback of belief/disbelief had no significant effect on memory. 


\subsection{Self-Assessed Abilities to Tell and Detect Lies Tell Truths and Believe Others}

The means and standard deviations of the ability assessments are presented in Table 1 . Table 1 show that the ratings in the two sessions are very similar. Specifically, test-retest correlations computed for of the four selfassessments are: tell-lies $r_{(100)}=.67$; detect-lies $r_{(100)}=.72$; believe others $r_{(100)}=.67$; and tell-truths $r_{(100)}=.69$. All correlations are significant at the .001 level.

In spite of the similarity, the second assessment might have been affected by the experimental procedure. It was therefore decided to use only the first session ratings (before the human interrogation) to further analyze the effects of ability assessments.

Table 1 show that in the first session participants assessed their truth-related abilities higher than their lierelated abilities. Using a matched samples t-test the difference is significant, $\mathrm{t}_{(99)}=3.8, p<.001$. The gap may be explained by the extreme assessments of the truth telling ability (very high) and the lie telling ability (considerably low). The difference between these two assessments is significant, $\mathrm{t}_{(99)}=9.2, p<.001$.

\subsection{Analysis of the Physiological Indices}

There may be large individual differences in physiological responding. To control for these differences and permit a meaningful summation of participant responses, all responses to each CIT multiple choice questions were transformed into within-subject standard scores relative to the respective means and standard deviations. Standard scores were computed for each of the three physiological indices (SCR, FPWL, and RLL). Essentially, standardization transformation was similar to all three measures, but because responses are indicated by smaller rather than larger RLLs and FPWLs, all these $\mathrm{Z}$ scores were multiplied by -1 .

Mean standardized responses to the critical alternatives were computed for each participant across CIT series. Mean scores across participants within each experimental condition served as the detection score of that condition. The physiological data were gathered and analyzed irrespective of participant memory to the crime-related items to avoid inflation of detection efficiency. The mean standard scores computed for each physiological measure are displayed in Table 2.

In order to assess whether the guilty participants responded to critical items more than the informed innocents, and whether interrogator belief or disbelief affected these responses, a multivariate analysis of variance (MANOVA) was employed with Guilt (guilty, innocents) and Feedback (belief, disbelief) as the independent factors and SCR, FPWL, and RLL as the dependent factors. For the purpose of the analysis, the distributions of the mean $Z$ scores, computed for each participant across all the items of the relevant profile, were gathered separately for each physiological measure.

A significant effect for Guilt was obtained: $\mathrm{F}_{(1,96)}=6.48, p=.012, p=.06$, when RLL was considered. The results indicated that RLL responses of guilty participants to critical items (mean $=.22$, $\mathrm{SD}=.32$ ), were relatively larger than those of informed innocents (mean $=.06, \mathrm{SD}=.27$ ). All other guilt and feedback effects did not reach statistical significance.

Table 1. Means (and SDs) of self-assessed truths/lies telling and detecting abilities in the two sessions of the experiment.

\begin{tabular}{|c|c|c|c|c|c|c|c|}
\hline & Tell lies & Detect lies & Tell truths & Believe others & Lies & Truths & Total \\
\hline \multicolumn{8}{|c|}{ First session (before the interrogation) } \\
\hline Mean & 47.5 & 63.8 & 68.0 & 58.8 & 55.6 & 63.4 & 59.5 \\
\hline $\mathrm{SD}$ & 20.2 & 20.1 & 16.8 & 20.0 & 16.5 & 13.9 & 11.4 \\
\hline \multicolumn{8}{|c|}{ Second session (after the polygraph test) } \\
\hline Mean & 49.8 & 63.8 & 67.8 & 59.9 & 56.8 & 63.8 & 60.3 \\
\hline $\mathrm{SD}$ & 20.9 & 19.7 & 16.8 & 19.3 & 17.2 & 12.1 & 11.2 \\
\hline \multicolumn{8}{|c|}{ Across sessions } \\
\hline Mean & 48.6 & 63.8 & 67.9 & 59.3 & 56.2 & 63.6 & 59.9 \\
\hline $\mathrm{SD}$ & 18.7 & 18.4 & 15.5 & 18.2 & 15.6 & 12.1 & 10.6 \\
\hline
\end{tabular}


Table 2. Means (and SDs) of SCR, RLL and FPWL z-scores responses elicited to critical items during the GAT.

\begin{tabular}{|c|c|c|c|}
\hline \multicolumn{4}{|c|}{ Interrogators' feedback } \\
\hline & Believed & Disbelieved & Across belief \\
\hline \multicolumn{4}{|c|}{ Guilty participants } \\
\hline SCR & $.28(.40)$ & $.27(.52)$ & $.27(.46)$ \\
\hline RLL & $.23(.31)$ & $.20(.34)$ & $.22(.32)$ \\
\hline FPWL & .19 (.38) & $.20(.32)$ & $.19(.35)$ \\
\hline \multicolumn{4}{|c|}{ Informed innocents } \\
\hline SCR & $.17(.38)$ & $.24(.47)$ & $.20(.43)$ \\
\hline RLL & $.07(.30)$ & $.05(.24)$ & $.06(.27)$ \\
\hline FPWL & .05 (.33) & $.21(.33)$ & $.13(.34)$ \\
\hline \multicolumn{4}{|c|}{ Across guilt } \\
\hline SCR & $.22(.39)$ & $.25(.49)$ & $.24(.44)$ \\
\hline RLL & $.15(.31)$ & $.13(.30)$ & $.14(.31)$ \\
\hline FPWL & $.12(.36)$ & $.20(.32)$ & $.16(.34)$ \\
\hline
\end{tabular}

Note: RLL stands for the unobtrusive respiration back measure.

\subsection{Signal Detection Theory (ROC) Analysis}

To examine if the insignificant results are due to the statistical method that did not employ a control group, we used another method derived from Signal Detection Theory. This method entitled the Receiver Operating Characteristic (ROC) procedure, has been employed before in CIT studies (e.g., Ben-Shakhar, 1977; Elaad, 2010; Elaad \& Ben-Shakhar, 1989, 1997; Verschuere et al., 2007; Vossel et al., 2003), and was recommended by the National Research Council Report (2003) as an appropriate method for describing the diagnostic value of polygraph tests. In signal detection theory terms, detection efficacy is defined as the degree of separation between the distributions of the responses to the critical items produced by experimental and control participants.

In the absence of a control condition (uninformed innocent participants), we followed the procedure suggested by Meijer, Smulders, Johnston, and Merckelbach (2007) to create a simulated innocent group by randomly drawing eleven values from a standard normal distribution (mean $=0$, standard deviation $=1$ ). Two values (representing the responses to the critical item in the first and second repetition) were standardized relative to the mean and standard deviation of all eleven responses and then were averaged. The process was repeated six times (representing six questions). The average of these six values represented the score of one control participant. In this way, a control group comprised of 50 innocent participants was created.

The mean $\mathrm{Z}$ scores distributions computed for each participant across all the items of the relevant profile, were calculated for each physiological measure. Also the distributions of the mean $\mathrm{Z}$ scores computed for each of the simulated control subjects were determined. ROC curves were then generated on the basis of these distributions and the areas under these ROC curves, along with the corresponding 95\% confidence intervals, were computed (see Bamber, 1975). The area statistic signify the detection efficacy of participants across all possible cutoff points. The assumed values range between 0 and 1 , so that an area of 1 indicates a perfect separation between the two distributions, whereas an area of 0.5 indicates complete overlap of the two distributions.

ROC statistics computed for each physiological measure (SCR, FPWL, RLL) of the four experimental conditions are presented in Table 3. It is easy to see that all ROC areas computed for guilty participants are significantly larger than chance (the lower bounds of the ROC areas are no less than 0.5). Specifically, guilty participants responded to the critical information at a significantly higher level than the simulated subjects that formed the control condition. Similar results were obtained for informed innocents with the SCRs. Specifically informed innocents elicited larger SCRs to the critical information than did the simulated control group. The areas under 
Table 3. Areas under the ROC curves and related statistics computed for SCR, RLL and FPWL z-score responses to the critical items.

\begin{tabular}{|c|c|c|c|c|c|c|}
\hline \multicolumn{7}{|c|}{ Interrogators' feedback } \\
\hline & \multicolumn{2}{|r|}{ Believed } & \multicolumn{2}{|r|}{ Disbelieved } & \multicolumn{2}{|c|}{ Across feedback } \\
\hline & Area & $95 \%$ CI & Area & $95 \%$ CI & Area & $95 \%$ CI \\
\hline \multicolumn{7}{|c|}{ Guilty participants } \\
\hline SCR & .728 & $.595-.861$ & .654 & $.508-.801$ & .691 & $.586-.797$ \\
\hline RLL & .758 & $.629-.887$ & .704 & $.570-.838$ & .731 & $.631-.831$ \\
\hline FPWL & .698 & $.549-.846$ & .710 & $.583-.837$ & .704 & $.600-.807$ \\
\hline \multicolumn{7}{|c|}{ Informed innocents } \\
\hline SCR & .644 & $.502-.786$ & .711 & $.560-.862$ & .678 & $.569-.786$ \\
\hline RLL & .578 & $.434-.723$ & .582 & $.441-.724$ & .580 & $.468-.693$ \\
\hline FPWL & .569 & $.425-.713$ & .743 & $.611-.876$ & .656 & $.548-.764$ \\
\hline \multicolumn{7}{|l|}{ Across } \\
\hline SCR & .686 & $.581-.791$ & .683 & $.574-.792$ & .656 & $.568-.743$ \\
\hline RLL & .668 & $.561-.776$ & .643 & $.546-.752$ & .680 & $.596-.764$ \\
\hline FPWL & .633 & $.522-.744$ & .726 & $.627-.826$ & .712 & $.629-.795$ \\
\hline
\end{tabular}

Note: RLL stands for the unobtrusive respiration back measure.

the ROC curve that were computed for RLLs were not significantly different from chance. For comparing two ROC areas, we used a method proposed by Hanley and McNeil (1983). It appeared that the RLL area computed for guilty participants was significantly $(Z=1.98)$ larger than the corresponding area computed for informed innocent participants. Again, SCR and FPWL did not show significant guilt or feedback effects.

\subsection{Self-Assessed Lying and Truth Telling Abilities and Tonic SCL in the Rest Period}

The subjective nature of questionnaires and the problem of demand characteristics would suggest the addition of a more objective method to examine the contribution of the self-assessed lying and truth telling abilities on physiological responsivity. This can be achieved by looking at the tonic responses of the skin conductance level (SCL) defined in Mho- $\mho$ units. Three skin conductance baseline scores were recorded in the initial two min. rest period. The mean of these scores defined the tonic autonomic reactivity of the participant.

Since the second self-assessment of the abilities could have been affected by the human interrogation and the polygraph test, only the self-assessed lying and truth telling abilities of the first session were entered as independent variables in a multiple regression analysis. The self-assessed ability to tell lies convincingly positively contributed to the magnitude of SCL elicited in the rest period by guilty participants ( $\beta=.36, t=2.64, p=.011$ ). The self-assessed ability to convince when telling the truth did not contribute to SCL magnitude of guilty participants $(\beta=-.07, \mathrm{t}=-.52, p=\mathrm{ns})$. For innocent participants the self-assessed abilities to tell lies and truths did not contribute to SCL. In summary, during the rest period guilty but not innocent participants who assessed high their lie-telling ability were more aroused (larger SCL) than their lower lie-telling ability counterparts.

\subsection{Self-Assessed Lie/Truth-Telling Abilities and Relative Physiological Responses to Critical Items}

To examine the contribution of the self-assessed abilities to the critical relative responses, guilty and informed innocents were separated (each $\mathrm{N}=50$ ). Three multiple regressions were conducted one for each physiological response. For this purpose only the four self-assessed abilities of the first session were entered as independent variables. For guilty participants, the hierarchical regression model for predicting SCRs was significant $\mathrm{F}_{(4,45)}=$ $3.19, p=.002$, which accounted for $22.1 \%$ of the variance. The self-assessed ability to tell lies positively contributed to the relative magnitude of SCRs elicited to the critical items, $(\beta=.40, \mathrm{t}=2.76, p=.008)$.

As to informed innocents, the hierarchical regression model for predicting SCRs was marginally significant, 
$\mathrm{F}_{(4,45)}=2.17, p=.09$, which accounted for $16.1 \%$ of the variance. The self-assessed ability to tell the truth convincingly negatively contributed to the relative magnitude of the SCRs $(\beta=-.43, \mathrm{t}=-2.58, p=.013)$. The hierarchical regression models for predicting RLL responses for both guilty and innocent participants were not significant $\left(\mathrm{F}_{(4,45)}=1.88\right.$ and $\mathrm{F}_{(4,45)}=1.49$, respectively). Similarly, the hierarchical regression models for predicting FPWL responses were not significant $\left(\mathrm{F}_{(4,45)}=1.89\right.$ and $\mathrm{F}_{(4,45)}=0.53$, for the respected guilty and innocent groups).

\section{Discussion}

The current study explores the physiological responses to critical items in the GAT under more realistic conditions than many previous CIT laboratory studies. To this end, the test was delayed for 1 - 14 days and participants were not reminded of the critical items before the polygraph test. As expected, participants remembered less critical items than in standard CIT experiments where the test was administered immediately after the mock-crime. It is tempting to explain the relatively low detection efficiency in the current study with the declined memory for critical items. However, when the reported memory was correlated with the relative response magnitude of each of the three measures, only SCRs showed a slight association, $\mathrm{r}_{(100)}=.19, p=.053$. RLL ( $\mathrm{r}_{(100)}$ $=.05)$ and FPWL $\left(\mathrm{r}_{(100)}=.07\right)$ showed actually no link between reported memory and responses.

Guilty participants remembered more critical items than did informed innocents. This is consistent with the results of Gamer, Kosiol, and Vossel (2010) who reported that after two weeks, active handling of crime relevant items strengthened the memory of guilty participants to these items. Reading the descriptions of the items by informed innocents gave rise to forgetting more items. From an applied perspective, this is encouraging: It is helpful to know that informed innocents tend to forget critical information whereas guilty suspects tend to forget less.

Table 2 and Table 3 reveal that SCR emerged as the most efficient measure. SCR superiority is consistent with earlier accounts (see, Meijer, Klein-Selle, Elber, \& Ben-Shakhar, 2014, for a review). Generally, guilty examinees elicited larger responses to the critical items than informed innocents although only the RLL responses were significantly different. The disbelieving manipulation failed to present significant response differences.

In previous studies an attempt was made to consider only the remembered items (e.g., Elaad, 2009). However, such a practice impairs our attempt to create conditions that better resemble realistic conditions and as indicated above, reported memory showed at best a minor associated with physiological responding. Therefore, when applying the CIT, all items that are considered to be good items should be taken into account. Guilty participants elicited larger RLL responses to the critical items than did informed innocents. Still, it is not clear why RLL responses showed a significant guilt difference whereas SCRs and FPWL responses did not. This is particularly intriguing because Gamer et al. (2010) in a delayed GAT setting and Bradley and Rettinger (1992) in an immediate GAT setting found significant guilt differences in the electro dermal data, but not in the respiration pattern.

Although the CIT is predominantly based on orientation (Lykken, 1974), mental processes other than orientation such as attention, motivation, deceptive answering, and inhibition were identified as involved in information concealment (e.g., Ambach, Stark, Peper, \& Vaitl, 2008; Elaad \& Ben-Shakhar, 1991; Verschuere et al., 2007). More recently, it was suggested that each physiological measure might reflect a different sub-process of the CIT (Klein-Selle et al., 2016). Specifically, skin conductance predominantly reflect OR and heart rate and respiration responses primarily reflect RI. Continuing this contention we may speculate that inhibition attempts by guilty but not by informed innocent participants may account for the RLL results. The role of sub-processes such as inhibition should be further studied in the context of the CIT in general and the GAT in particular.

To maintain the relatively realistic situation we added explicit disbelief of a human interrogator to the experimental situation. In actual settings, every examinee that undergoes a polygraph test is a suspect and the interrogator makes it clear that he/she has doubts as to the veracity of the suspect's story. To try and change the attitude of the interrogator, the examinee must pass the polygraph test. The effect of such disbelief is highly relevant to the study of the CIT, and it is vital to examine how disbelief affects the physiological responses of guilty and informed innocent participants. As far as we know, this is the first study to undertake this crucial research goal.

It was found that the disbelief manipulation had no significant effect on the physiological responses to critical items. The manipulation check shows that the belief/disbelief manipulation was strong and effective in the first 
session of the experiment, immediately after the interrogation. Specifically, when participants were asked to indicate their feelings on the PANAS questionnaire believed participants enhanced positive emotions and disbelieved participants increased negative emotions.

Inspection of Table 2 and Table 3 shows that although insignificant, SCR and FPWL responses of disbelieved innocent participants were substantially larger than those of believed innocents. It seems that traces of the feedback manipulation lasted into the polygraph test. It may be further speculated that if the polygraph test would have been administered immediately after the interrogation the feedback factor could have produced significant changes in the physiological responding. This possibility has to be examined in future research.

The significant weakening of the disbelieving effect in the second phase of the study can be explained by the nature of a laboratory experiment with its ethical limitations. Unlike actual testing, the present participants knew that whatever the outcome, it would have no consequences on their well-being. Therefore, their elevated emotional state after the interrogation did not last.

The state of suspicion raises a question about the power of the perceived ability to tell lies convincingly on guilty examinees in the CIT and the influence of the ability to persuade others when telling the truth on innocent examinees.

As expected, the self-assessed truth telling ability was ranked high and the lie telling ability was ranked low. The high assessment of the ability to tell the truth convincingly was previously reported among various groups such as prisoners (Elaad, 2009), police investigators (Elaad, 2009), adolescents (Elaad et al., 2012), students (Elaad, 2011), and laypersons (Elaad, 2009). The effect was explained by the "illusion of transparency" (Gilovich, Savitsky, \& Medvec, 1998) which indicates that while communicating, speakers are anchored to their own internal feelings. Although they realize that receivers are not exposed to the same feelings, their adjustment is insufficient (Tversky \& Kahneman, 1974). Speakers then still tend to believe that the recipient has the ability to detect their internal states and find out that they are telling the truth. Results may also be explained by the persons desire to sustain a positive self-image (Kaplar \& Gordon, 2004). As mentioned, the ability to convince when telling the truth is a wanted quality.

The rather low rated lie-telling ability was previously addressed (Ekman \& O’Sullivan, 1991; Elaad, 2003, 2011; Vrij, 2008) and was found among various groups of participants (Elaad, 2003, 2009, 2011; Elaad et al., 2012). However, it was also observed that a group of police investigators rated their lie-telling abilities higher than other people (Elaad, 2009). The low-assessed lie-telling ability was also explained by the illusion of transparency (Gilovich et al., 1998). As people's adjustment is insufficient they are concerned that the recipient has the ability to discern their inner feelings and thoughts and detect their lies. Safeguarding a positive self-image as an honest person also contributes to the low lie-telling assessment.

One important contribution of the present study is its attempt to link self-assessed abilities and physiological responsivity. It was found that the self-assessed ability to tell lies convincingly by guilty participants positively contributed to SCL in the rest period and to the relative magnitude of SCRs elicited to the critical items in the test itself. Specifically, participants who are confident in their ability to lie successfully elicited larger SCRs to critical items than less confident participants. It may be suggested that low lie-telling ability raters acknowledge the fact that the polygraph will detect their involvement with the critical items and make no effort to change this outcome. The smaller group of high lie-telling ability raters may have felt that they have the ability to influence the polygraph outcome which results in higher tonic SCL or enhanced arousal before the test, and focused attention to the critical items during the test. Still, the self-assessed lie-telling ability did not affect RLL and FPWL responses which moderate the attention explanation.

The self-assessed ability to be convincing when telling the truth negatively contributed to the relative magnitude of SCRs. Results indicate that the smaller group of low truth telling raters elicited larger responses to the critical items than their high rater counterparts. Again, results may be explained by differential attention. Innocent participants with low perception of their ability to persuade others when they tell the truth attend to the critical items, wondering if their truthful denial of involvement with this item stands. People who feel able to persuade when telling the truth have less doubts that their truthful denial passed the test and therefore pay less attention to its presentation. Still, it is not clear why the added attention did not affect RLL and FPWL responses.

\section{Limitations of the Present Study}

The present study tried to simulate real life conditions as far as possible. By doing so, limitations of the experi- 
mental research were highlighted. For ethical reasons the experiment cannot extend negative emotions of participants beyond here and now. This was acknowledged, and attenuated feedback effects on the physiological responses were expected. Still it was hypothesized that the investigator disbelief of informed innocents would elicit some enhanced physiological responsivity. Although insignificant, disbelieved innocent participants responded with larger SCR and FPWL responses to critical items than believed innocents. Other indicators also showed traces of the feedback manipulation that lasted into the polygraph test.

Although trying to imitate actual CIT testing, the present study is still a laboratory experiment with low stakes. Participants were well aware that failing the test will have no damaging consequences. Specifically, the threat is less than the threats that criminal suspects usually experience during actual testing. This is well demonstrated when on a 0 - 100 scale, representing the amount of guilt participants felt, those in the guilty group rated themselves at 57.6 which is close to the mid-point. This can be interpreted as reflecting low sense of guilt. Still, the guilt manipulation was successfully implemented as the mean guilt rating of innocents (18.2) was much lower than that of guilty participants. Similarly, the present interrogation was not anything like a police interrogation which involves getting suspects to provide an account of their knowledge regarding the crime. However, the aim of the interrogation was to manipulate belief/disbelief which was successfully done. From a practical perspective, the applied value of the present results for actual testing should be considered with caution.

We employed undergraduate students enrolled in an "introduction to psychology" course and promised them course credit. This is not the typical population that is expected in real life polygraph testing. It may be further argued that psychology students may have some knowledge on psychology studies and may have guessed the purpose of the preliminary interrogation manipulation, particularly as the interrogation was performed by fellow students and might have rendered their participation as interrogees more game-like. However, immediately after the interrogation participants who were disbelieved felt worse than participants who were believed. Further, participants were largely at the first year of their studies, while the experimenters were at the third year. In addition, experimenters and participants were not acquainted.

Finally, the present sample consisted mainly of female participants. Although females were no more or less inclined than males to respond to critical items in the CIT, this dictates caution when considering the applied value of the results to largely male suspects in police interrogations.

\section{Conclusion}

In spite of the mentioned limitations, some introduction of disbelief into the CIT has been observed. This may suggest that more research is needed to unfold the believing and disbelieving effects on the CIT examination. The guilt manipulation was more productive and displayed significant RLL responses. Another contribution of the present study is the obtained association between self-assessed abilities to tell lies and truths and SCRs in the GAT. The present results justify additional scientific efforts to better understand these relations.

\section{Acknowledgements}

This research was funded by a grant from the Ariel University Research Authority. We would like to thank Tchiya Rosenman, or Mitrani, Gonen Chen, and Roni Avisar for their contribution during the data collection and analysis.

\section{References}

Ambach, W., Stark, R., Peper, M., \& Vaitl, D. (2008). An Interfering Go/No-Go Task Does Not Affect Accuracy in a Concealed Information test. International Journal of Psychophysiology, 68, 6-16. http://dx.doi.org/10.1016/j.ijpsycho.2007.11.004

Bamber, D. (1975). The Area above the Ordinal Dominance Graph and the Area below the Receiver Operating Characteristic Graph. Journal of Mathematical Psychology, 12, 387-415. http://dx.doi.org/10.1016/0022-2496(75)90001-2

Ben-Shakhar, G. (1977). A Further Study of the Dichotomization Theory in Detection of Information. Psychophysiology, 14, 408-413. http://dx.doi.org/10.1111/j.1469-8986.1977.tb02974.x

Ben-Shakhar, G. (2012). Current Research and Potential Applications of the Concealed Information Test: An Overview. Frontiers in Psychology, 3, 1-11. http://dx.doi.org/10.3389/fpsyg.2012.00342

Ben-Shakhar, G., \& Elaad, E. (2003). The Validity of Psychophysiological Detection of Information with the Guilty Know- 
ledge Test: A Meta-Analytic Review. Journal of Applied Psychology, 88, 131-151. http://dx.doi.org/10.1037/0021-9010.88.1.131

Ben-Shakhar, G., Gronau, N., \& Elaad, E. (1999). Leakage of Relevant Information to Innocent Examinees in the GKT: An Attempt to Reduce False-Positive Outcomes by Introducing Target Stimuli. Journal of Applied Psychology, 84, 651-660. http://dx.doi.org/10.1037/0021-9010.84.5.651

Bradley, M. T., MacLaren, V. V., \& Carle, S. B. (1996). Deception and Nondeception in Guilty Knowledge and Guilty Actions Polygraph Tests. Journal of Applied Psychology, 81, 153-160. http://dx.doi.org/10.1037/0021-9010.81.2.153

Bradley, M. T., \& Rettinger, J. (1992). Awareness of Crime Relevant Information and the Guilty Knowledge Test. Journal of Applied Psychology, 77, 55-59. http://dx.doi.org/10.1037/0021-9010.77.1.55

Bradley, M. T., \& Warfield, J. F. (1984). Innocence, Information, and the Guilty Knowledge Test in the Detection of Deception. Psychophysiology, 21, 683-689. http://dx.doi.org/10.1111/j.1469-8986.1984.tb00257.x

Carmel, D., Dayan, E., Naveh, A., Raveh, O., \& Ben-Shakhar, G. (2003). Estimating the Validity of the Guilty Knowledge Test from Simulated Experiments: The External Validity of Mock Crime Studies. Journal of Experimental Psychology: Applied, 9, 261-269. http://dx.doi.org/10.1037/1076-898x.9.4.261

Ekman, P., \& O’Sullivan, M. (1991). Who Can Catch a Liar? American Psychologist, 46, 913-920. http://dx.doi.org/10.1037/0003-066X.46.9.913

Elaad, E. (1997). Polygraph Examiner Awareness of Crime-Relevant Information and the Guilty Knowledge Test. Law and Human Behavior, 21, 107-120. http://dx.doi.org/10.1023/A:1024822211587

Elaad, E. (2003). Effects of Feedback on the Overestimated Capacity to Detect Lies and the Underestimated Ability to Tell Lies. Applied Cognitive Psychology, 17, 349-363. http://dx.doi.org/10.1002/acp.871

Elaad, E. (2009). Lie-Detection Biases among Male Police Investigators, Prisoners, and Laypersons. Psychological Reports, 105, 1047-1056. http://dx.doi.org/10.2466/PR0.105.F.1047-1056

Elaad, E. (2010). Effects of Perceived Reliability and Generalization of Crime-Related Information on Detection in the Concealed Information Test. International Journal of Psychophysiology, 75, 295-303.

http://dx.doi.org/10.1016/j.ijpsycho.2010.01.001

Elaad, E. (2011). Effects of Feedback on Self-Assessed and Actual Abilities to Tell Lies. In A. E. Hasselm (Ed.), Crime: Causes, Types and Victims (pp. 155-166). Hauppauge, NY: Nova Science Publishers,

Elaad, E. (2013). Effects of Goal-and Task-Oriented Motivation in the Guilty Action Test. International Journal of Psychophysiology, 88, 82-90. http://dx.doi.org/10.1016/j.ijpsycho.2013.02.004

Elaad, E. (2015). The Distrusted Truth: Examination of Challenged Perceptions and Expectations. Psychology, 6, 560-571. http://dx.doi.org/10.4236/psych.2015.65054

Elaad, E., \& Ben-Shakhar, G. (1989). Effects of Motivation and Verbal Response Type on Psychophysiological Detection of Information. Psychophysiology, 26, 442-451. http://dx.doi.org/10.1111/j.1469-8986.1989.tb01950.x

Elaad, E., \& Ben-Shakhar, G. (1991). Effects of Mental Countermeasures on Physiological Detection in the Guilty Knowledge Test. International Journal of Psychophysiology, 11, 99-108. http://dx.doi.org/10.1016/0167-8760(91)90001-E

Elaad, E., \& Ben-Shakhar, G. (1997). Effects of Item Repetitions and Variations on the Efficiency of the Guilty Knowledge Test. Psychophysiology, 34, 587-596. http://dx.doi.org/10.1111/j.1469-8986.1997.tb01745.x

Elaad, E., \& Ben-Shakhar, G. (2006). Finger Pulse Waveform Length in the Detection of Concealed Information. International Journal of Psychophysiology, 61, 226-234. http://dx.doi.org/10.1016/j.ijpsycho.2005.10.005

Elaad, E., \& Ben-Shakhar, G. (2008). Covert Respiration Measures for the Detection of Concealed Information. Biological Psychology, 77, 284-291. http://dx.doi.org/10.1016/j.biopsycho.2007.11.001

Elaad, E., Ginton, A., \& Jungman, N. (1992). Detection Measures in Real-Life Criminal Guilty Knowledge Tests. Journal of Applied Psychology, 77, 757-767. http://dx.doi.org/10.1037/0021-9010.77.5.757

Elaad, E., Lavy, S., Cohenca, D., Berholz, E., Thee, P., \& Ben-Gigi, Y. (2012). Lies, Truths, and Attachment Orientations in Late Adolescence. Personality and Individual Differences, 52, 670-673. http://dx.doi.org/10.1016/j.paid.2011.12.018

Ellwanger, J., Rosenfeld, J. P., Sweet, J. J., \& Bhatt, M. (1996). Detecting Simulated Amnesia for Autobiographical and Recently Learned Information Using the P300 Event-Related Potential. International Journal of Psychophysiology, 23, 9-23. http://dx.doi.org/10.1016/0167-8760(96)00035-9

Gamer, M. (2010). Does the Guilty Actions Test Allow for Differentiating Guilty Subjects from Informed Innocents? A Re-Examination. International Journal of Psychophysiology, 76, 19-24. http://dx.doi.org/10.1016/j.ijpsycho.2010.01.009

Gamer, M., Kosiol, D., \& Vossel, G. (2010). Strength of Memory Encoding Affects Physiological Responses in the Guilty Action Test. Biological Psychology, 83, 101-107. http://dx.doi.org/10.1016/j.biopsycho.2009.11.005

Gilovich, T., Savitsky, K., \& Medvec, V. (1998). The Illusion of Transparency: Biased Assessments of Others’ Ability to 
Read One’s Emotional States. Journal of Personality and Social Psychology, 75, 332-346. http://dx.doi.org/10.1037/0022-3514.75.2.332

Hanley, J. A., \& McNeil, B. J. (1983). A Method of Comparing the Areas under Receiver Operating Characteristic (ROC) Curves Derived from the Same Cases. Radiology, 148, 839-843. http://dx.doi.org/10.1148/radiology.148.3.6878708

Kaplar, M. E., \& Gordon, A. K. (2004). The Enigma of Altruistic Lying: Perspective Differences in What Motivates and Justifies Lie Telling within Romantic Relationships. Personal Relationships, 11, 489-507.

http://dx.doi.org/10.1111/j.1475-6811.2004.00094.x

Kassin, S. M. (2005). On the Psychology of Confessions. American Psychologist, 60, 215-228. http://dx.doi.org/10.1037/0003-066X.60.3.215

Klein-Selle, N., Verschuere, B., Kindt, M., Meijer, E., \& Ben-Shakhar, G. (2016). Orienting versus Inhibition in the Concealed Information Test: Different Cognitive Processes Drive Different Physiological Measures. Psychophysiology, 53, 579-590. http://dx.doi.org/10.1111/psyp.12583

Lykken, D. T. (1974). Psychology and the Lie Detector Industry. American Psychologist, 29, 725-739. http://dx.doi.org/10.1037/h0037441

Lykken, D. T. (1998). A Tremor in the Blood: Uses and Abuses of the Lie Detector. New York: Plenum Press.

Lynn, R. (1966). Attention, Arousal and the Orientation Reaction. Oxford: Pergamon Press.

Meijer, E. H., Klein-Selle, N., Elber, L., \& Ben-Shakhar, G. (2014). Memory Detection with the Concealed Information Test: A Meta-Analysis of Skin Conductance, Respiration, Heart Rate, and P300 Data. Psychophysiology, 51, 879-904. http://dx.doi.org/10.1111/psyp.12239

Meijer, E. H., Smulders, J. E., Johnston, E., \& Merckelbach, H. L. G. J. (2007). Combining Skin Conductance and Forced Choice in the Detection of Concealed Information. Psychophysiology, 44, 814-822. http://dx.doi.org/10.1111/j.1469-8986.2007.00543.x

Meissner, C. A., \& Kassin, S. M. (2002). “He’s Guilty!”: Investigator Bias in Judgments of Truth and Deception. Law and Human Behavior, 26, 469-480. http://dx.doi.org/10.1023/A:1020278620751

Nahari, G., \& Ben-Shakhar, G. (2011). Psychophysiological and Behavioral Measures for Detecting Concealed Information: The Role of Memory for Crime Details. Psychophysiology, 48, 733-744.

http://dx.doi.org/10.1111/j.1469-8986.2010.01148.x

National Research Council Report (2003). The Polygraph and Lie Detection. Committee to Review the Scientific Evidence on the Polygraph, Division of Behavioral and Social Sciences and Education, Washington DC: The National Academies Press.

Rosenfeld, J. P., Hu, X., \& Pedersen, K. (2012). Deception Awareness Improves P300-Based Deception Detection in Concealed Information Tests. International Journal of Psychophysiology, 86, 114-121. http://dx.doi.org/10.1016/j.ijpsycho.2012.06.007

Sai, L., Lin, X., Rosenfeldd, J. P., Sang, B., Hu, X., \& Fu, G. (2016). Novel, ERP-Based, Concealed Information Detection: Combining Recognition Based and Feedback-Evoked ERPs. Biological Psychology, 114, 13-24. http://dx.doi.org/10.1016/j.biopsycho.2015.11.011

Sokolov, E. N. (1963). Perception and the Conditioned Reflex. Oxford: Pergamon Press.

Tversky, A., \& Kahneman, D. (1974). Judgment under Uncertainty: Heuristics and Biases. Science, 185, 1124-1131. http://dx.doi.org/10.1126/science.185.4157.1124

Verschuere, B., \& Ben-Shakhar, G. (2011). Theory of the Concealed Information Test. In B. Verschuere, G. Ben-Shakhar, \& E. Meijer (Eds.), Memory Detection: Theory and Application of the Concealed Information Test (pp. 128-148). Cambridge: Cambridge University Press. http://dx.doi.org/10.1017/CBO9780511975196.008

Verschuere, B., Crombez, G., Koster, E., Van Bockstaele, B., \& De Clercq, A. (2007). Startling Secrets: Startle Eyeblink Modulation by Concealed Crime Information. Biological Psychology, 76, 52-60. http://dx.doi.org/10.1016/j.biopsycho.2007.06.001

Vossel, G., Gamer, M., Godert, H. W., \& Rill, H. G. (2003). The Efficiency of Detecting Concealed Information with the Guilty Knowledge Test: A Comparison of Different Physiological Variables and Non-Physiological Methods of Credibility Assessment Using Signal Detection Theory. Journal of Psychophysiology, 17, 184.

Vrij, A. (2008). Detecting Lies and Deceit: Pitfalls and Opportunities (2nd ed.). Chichester: Wiley.

Watson, D. (1988). Intraindividual and interindividual Analyses of Positive and Negative Affect: Their Relation to Health Complaints, Perceived Stress, and Daily Activities. Journal of Personality and Social Psychology, 54, 1020-1030.

http://dx.doi.org/10.1037/0022-3514.54.6.1020

Zvi, L., Nachson, I., \& Elaad, E. (2012). Effects of Coping and Cooperative Instructions on Guilty and Informed Innocents' 
Physiological Responses to Concealed Information. International Journal of Psychophysiology, 84, 140-148. http://dx.doi.org/10.1016/j.ijpsycho.2012.01.022

Zvi,L., Nachson,I., \& Elaad, E. (2015). The Concealed Information Test: Effects of Perceived Efficacy and Prospect of Success on Detection in the Guilty Action Test. International Journal of Psychophysiology, 95, 35-45.

http://dx.doi.org/10.1016/j.ijpsycho.2014.12.010

\section{Submit or recommend next manuscript to SCIRP and we will provide best service for you:}

Accepting pre-submission inquiries through Email, Facebook, Linkedin, Twitter, etc A wide selection of journals (inclusive of 9 subjects, more than 200 journals)

Providing a 24-hour high-quality service

User-friendly online submission system

Fair and swift peer-review system

Efficient typesetting and proofreading procedure

Display of the result of downloads and visits, as well as the number of cited articles

Maximum dissemination of your research work

Submit your manuscript at: http://papersubmission.scirp.org/ 